\title{
Integrating self-management into daily life following primary treatment: head and neck cancer survivors' perspectives
}

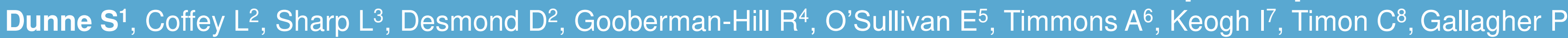
'School of Nursing and Human Sciences, Dublin City University, Ireland; ${ }^{2}$ Department of Psychology, National University of Ireland Maynooth, Co. Kildare, Ireland, ${ }^{3}$ Newcastle University, England; ${ }^{4}$ University
Bristol, United Kingdom; ${ }^{5}$ Cork Dental School and Hospitial, Ireland; ${ }^{\circ}$ National Cancer Registry Ireland, Cork, Ireland; 7 University Hospital Galway, Ireland; ${ }^{8 S t}$ James's Hospitial, Dublin, Ireland

\section{DCU

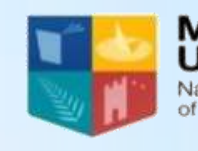 \\ Maynooth
University

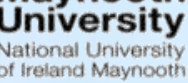

\section{Introduction}

- Cancer self-management is the "awareness and active participation by the person in their recovery, recuperation and rehabilitation, to minimise the consequences of treatment, and promote survival, health and well-being"1; p.6.

- Head \& Neck Cancer (HNC) survivors face unique challenges following treatment (e.g. facial disfigurement and eating, swallowing, breathing \& speech impairments) which strongly impact their physical, functional, social, and psychological wellbeing $^{2}$, and often require ongoing self-management ${ }^{3}$.

- However, little is currently known about how HNC survivors integrate self-management into their daily lives. Such research may identify how some HNC survivors successfully integrate self-management into their daily lives, while others do not.
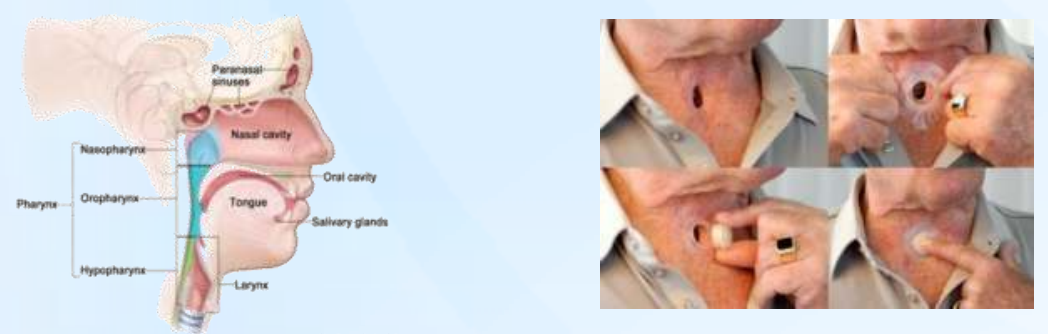

Results
罍CC

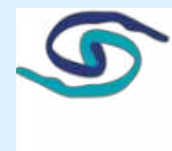
Cancer
Registry
Ireland

4. Galway University Hospitals

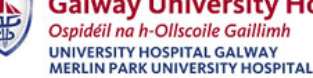

\section{Study Aim}

- To describe and characterise the processes through which HNC survivors attempt to integrate self-management into their daily lives following primary treatment.

\section{Methods}

- We conducted 26 semi-structured interviews with HNC survivors (17 males, 9 females; aged 30-77) from four healthcare sites across Ireland.

- HNC survivors had undergone surgery, radiation or chemotherapy, or a combination thereof targeting a range of different sites (larynx, pharynx, oral cavity, tonsils, tongue).

- All participants were asked open-ended questions about how they managed condition-related challenges they had encountered following HNC treatment.

- Interviews were audio-recorded (mean length: 1.5 hours), typically in patients' homes, and transcribed for thematic analysis ${ }^{4}$.
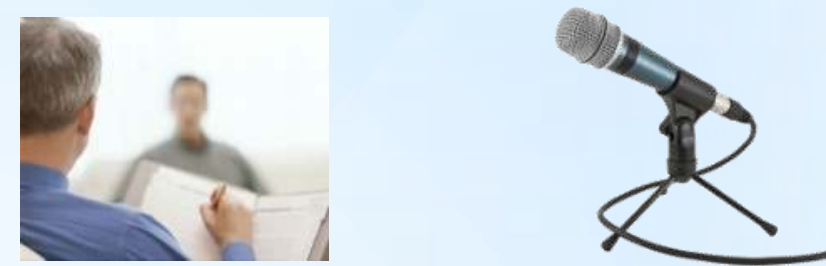

\section{4}

- We identified 6 themes relating to HNC survivors' attempts to integrate selfmanagement into daily life following primary treatment.

- Three of these themes relate to a sequential process of self-management integration, two relate to HNC survivors' difficulties integrating self-manage ment into daily life and the final over-arching theme relates to how HNC survivors interpret selfmanagement in the context of their daily lives.
Interpreting self-management
Prioritising recovery My job is to stay fit, eat well, sleep well, be positive. I was dying to get to six-monthly visits, because then I know I'm definitely getting better. It's like another milestone I have to make. [Eimear, 56 years]
Struggling to integrate selfmanagement

[I smoke] 10 to 15 a day. That's too much; none at all is the answer. I want to [give up] but it's very hard, especially after having a cup of tea, or sandwich; then the addiction's there straight away after. I've tried everything. Nothing seemed to work I tried even the chewing gum. Willpower is the only answer. I'll have to do something. I don't stop, [I would] surely [Eoghan, know how. If I could
Becoming an expert self-manager The exercises have to become second nature. I do them all the time. My trigger is: I'm driving the car, red traffic lights, do my exercises; brush my teeth, do my exercises; brush my hair, do my exercises... [Eimear, 56 years]

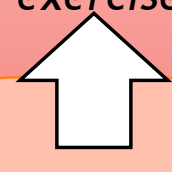

Trying out different self-management strategies It had been suggested to me that I take a product called [name removed]. Something to do with the nerve endings. I prefer not to take it, because it makes me very drowsy. I'm better off without it. [Nuala, 62 years]

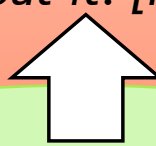

Grappling with having to self-manage

After I was released from hospital, the big worry was getting myself ready for self-care at home, how to clean [the tracheostomy site]. You know, keeping myself clean, and just getting on with your daily life - and being very self-aware of having this thing sticking out of your neck [...] and wondering what will happen if this goes wrong or if I can't manage. [Timothy, 57 years] illiss, any decision makies had to gradually go back into that. 'I have to go back to being a mother and a wife.' [Niamh, 49 years]

$$
64 \text { years] }
$$

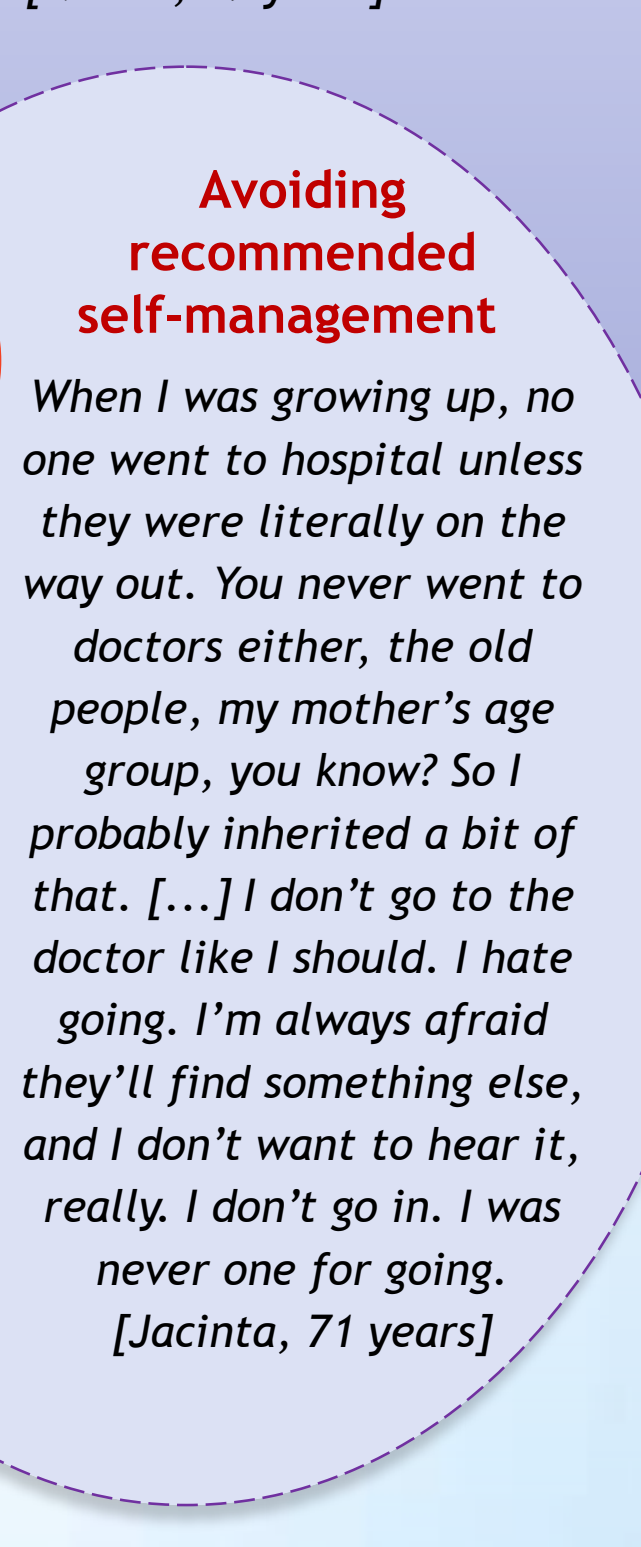

REFERENCES

'Davies N, Batehup L. Self-management support for cancer survivors: Guidance for developing interventions: An update of the evidence. 2010;London:Macmillan Group.

${ }^{2}$ Howren MB, Christensen AJ, Karnell LH, Funk GF. Psychological factors associated with head and neck cancer treatment and survivorship: Evidence and opportunities for behavioural medicine. $J$ Consult Clin Psychol. 2013:81(2):299-317.

${ }^{3}$ McCorkle R, Ercolano E, Lazenby M, Schulman-Green D, Schilling LS, Lorig K, Wagner EH. Self-management: Enabling and empowering patients living with cancer as a chronic illness. CA Cancer J Clin, 2011;61:50-62.

${ }^{4}$ Braun V, Clarke V. Using thematic analysis in psychology. Qual Res Psychol. 2006;3(2):77-101

\section{Conclusion}

- This is the first study to describe HNC survivors' attempts to integrate self-management into daily life treatment.

- The findings indicate that HNC survivors exhibit highly individualised approaches to self-management integration and abandon strategies that fail to meet their own specific needs. 